УдК 591.18:576.31+616.076

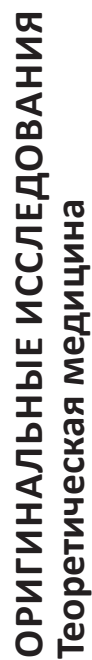

М.М. Горбунов, С.С. Целуйко, С.В. Зиновьев

ФГБОУ ВО Амурская ГМА

Минздрава России

г. Благовещенск

ВЛИЯНИЕ УЛЬТРАСТРУКТУРНЫХ ИЗМЕНЕНИЙ ВНУТРИКЛЕТОЧНЫХ ОРГАНЕЛЛ НА ЭВАКУАТОРНУЮ ФУНКЦИЮ МЕРЦАТЕЛЬНОГО ЭПИТЕЛИЯ И МЕТОД ОБНАРУЖЕНИЯ ЕЕ С ПОМОЩЬЮ КРИОБИОПСИИ

Болезни органов к числу наиболее

дыхания относятся распространенных заболеваний человека. Среди болезней органов дыхания большая часть приходится на острые респираторные вирусные инфекции, отягощенные бактериальной инфекцией, которые являются причиной многих осложнений [8]. Первым барьером на пути возбудителей является слизистая оболочка дыхательных путей. Именно в ней чаще всего разворачивается первичный воспалительный процесс и формируются предпосылки для дальнейшего распространения патологии [19].

Все отделы дыхательных путей покрыты реснитчатым эпителием. Мукоцилиарный клиренс является важнейшим звеном защиты дыхательных путей [36]. В составе слизистой оболочки дыхательных путей находятся не только реснитчатые, но также бокаловидные клетки, которые секретируют слизь, и базальные клетки. В норме клетки слизистой оболочки обновляются каждые 4-8 недель [6]. На каждой реснитчатой клетке находится до 200 ресничек длиной 5-7 мкм и шириной 0,2 мкм. Цилиарный эпителий, перицилиарный слой секрета и собственно слизь составляют функционально связанный комплекс, представляющий собой мукоцилиарную систему, которая является важнейшим механизмом естественной защиты респираторного тракта [23]. В норме реснички движутся координированно, формируя однонаправленный поток слизи [20, 34]. Несмотря на свои малые размеры, реснички способны продвигать слизь со скоростью до 0,5 $\mathrm{MM} / \mathrm{c}$, что составляет около $3 \mathrm{~cm}$ в минуту [9]. Впервые ультраструктура ресничек была описана Fawcett иPorterв1954 г.идополненаAfzeliusв 1959г.

Реснички представляют собой выросты клетки, центральную часть занимает аксонема, состоящая из 9 дублетов микротрубочек, в центре расположены отдельные микротрубочки [30]. Вдоль всей длины микротрубочек расположены диеновые ручки - внутренние и внешние, которые участвуют в преобразовании химической энергии АТФвмеханическую[11].Радиальныеспицымежду дублетами и центральной парой микротрубочек обеспечивают структурную устойчивость [2].

В основе изменений жизнедеятельности организма животных и человека при патологических процессах, состояниях и заболеваниях лежит нарушение функции клеток. В клетках реализуются процессы превращения энергии и еe использования для реализации генетических программ и обеспечения специализированных функций [29]. Одной из множества таких функций является участие клетки в колебательных движениях реснитчатого эпителия [9]. Выявление генеза заболеваний разной природы становится возможным лишь при изучении закономерностей изменений, происходящих на уровне молекул, субклеточных структур, клеток, органов, целостного организма. Кроме того, изучение патологии клетки ведет к познанию механизмов ее функциональных отправлений в обычных условиях. Так, результатом последних исследований биологии было открытиедвухсложнейших функциональных систем, контролирующих поведение нормальных клеток: системы проведения сигналов и системы внутриклеточной безопасности. В настоящий момент изучают прямое и опосредованное

Резюме На сегодняшний день накопилось достаточное количество литературных данных в области исследований морфологической структуры и функции мукоцилиарной системы воздухоносных путей человека и животных. Именно за счет этой системы создаются компенсаторные механизмы, позволяющие противостоять воздействию патогенных факторов внешней среды. В результате воздействия неблагоприятных факторов нарушается не только частота колебательных движений реснитчатого аппарата, но и внутриклеточные органеллы реснитчатых клеток, обслуживающие эту специализированную функцию. В настоящий момент имеются многочисленные методики, позволяющие обнаружить нарушения мукоцилиарного аппарата реснитчатых клеток. Однако наиболее перспективным является прижизненное изучение клеток с помощью метода замораживания скалывания, который позволяет в кратчайшие сроки дополнить картину изменений в органеллах клетки. Представленный литературный обзор является частью научной работы ЦНИЛ ФГБОУ ВО Амурская ГМА Минздрава России (Амурская ГМА) по изучению регенерационных процессов в дыхательной системе и направленной на дальнейшее исследование адаптационных механизмов.

Ключевые слова: мукоцилиарный клиренс, реснички, микротрубочки, мукоцилиарный транспорт, жидкий азот. 
Прямое действие касается нарушения структуры и функции органов-мишеней, подвергнутых действию патогенного фактора. Косвенное, опосредованное влияние связано с нарушением деятельности других клеток, органов и систем. Причинами прямых повреждений клеток могут быть физические, химические и биологические факторы [1]. Одной из причин прямых повреждений является температурное воздействие.

Значительное повышение или снижение температуры оказывает на клетку пагубное влияние, приводящее к повышенной проницаемости биологической мембраны. Понижение температуры среды ниже границ адаптации ведет к снижению обменных процессов или полному их прекращению [25]. Происходит образование свободных радикалов, повреждающих ферментные системы и структуру клеточных мембран. Токсины, образующиеся в результате действия патогенных микробов, способны блокировать рецепторы на поверхности мембран и подавлять функцию ионных каналов блокированием $\mathrm{K}^{+}$-, $\mathrm{Na}^{+}$- аденозинтрифосфатаз.

К опосредованному действию патогенных факторов относятся повреждения клеток, возникающих за счет образующейся цепи вторичных реакций после прямого повреждения клеток респираторного тракта. Одним из них являются иммунные реакции организма и изменения параметров жестких констант гомеостаза, что проявляется в повышении концентрации свободных радикалов [3]. Изменения, возникающие в клетке под влиянием повреждающих факторов, неоднозначны. Они могут нести черты специфичности, свойственные действию конкретного патогена, и быть неспецифическими, характерными для всех вредоносных факторов и для клеток любых тканей. Специфическим для действия механических факторов будет нарушение целостности субклеточных, клеточных структур, органа, ткани [18]. Неспецифические - это общие реакции клеток, начинающиеся сразу после воздействия патологии. Любое повреждение клетки вызывает резкое повышение проницаемости клеточных мембран, увеличение объема клетки, увеличение способности цитоплазмы и ядра связываться с красителями.

Поврежденные клетки выделяют большое количество биологически активных веществ, воздействующих на здоровые клеточные элементы, окружающие очаг повреждения. Эти биологически активные вещества получили название «медиаторы повреждения». К ним относятся гистамин, серотонин, брадикинин, простагландины, ацетилхолин, адреналин, ферменты [5]. Многие из этих биологически активных веществ способствуют развитию воспалительных и аллергических реакций.

Внутренняя структура реснитчатых клеток представляет собой сложную систему, в которой находятся специализированные образования, воспринимающие внешние сигналы, передающие их внутрь и реализующие ответную внутриклеточную реакцию, выделяющие различные метаболиты и собственные сигнальные молекулы. Эта многокомпонентная система состоит из плазматической мембраны, ядра и органоидов. В ответ на внешнее повреждение клетка, каки организм, реагируетнаэто, какединое целое. Тем не менее, в специализированных клетках преобладают изменения структуры и функций ее отдельных компонентов [7].

Плазматические мембраны, окружающие

\title{
INFLUENCE OF ULTRASTRUCTURAL CHANGES OF INTRA-CELLULAR ORGANELLES ON THE EVACUATOR FUNCTION OF THE CLINITED EPITELIUM AND METHOD OF THE DETECTION BY CRYOBIOPS
}

\author{
S.S. Tseluyko, M.M. Gorbunov, S.V. Zinoviev \\ FSBEI HE Amur SMA HM, Blagoveshchensk, Russia
}

Abstract To date, a sufficient amount of literary data has accumulated in the field of studies of the morphological structure and function of the mucociliary system of airways of a man and animals. Due to this system compensatory mechanisms are created that allow to resist the effects of pathogenic environmental factors. As a result of the influence of unfavorable factors, not only the frequency of oscillatory movements of the ciliary apparatus is damaget, but also the intracellular organelles of the ciliated cells that serve this specialized function. At the moment, there are numerous methods to detect disturbaces of the mucociliary apparatus of ciliated cells. However, the most promising is the lifetime study of cells with the help of the method of split freezing, which allows the picture to be supplemented in the shortest possible time, only by the emerging changes in the organelles of the cell. The presented literature review is part of the scientific work of CSRL of AGMA in the study of regeneration processes occurring in the respiratory system and aimed at further research of adaptation mechanisms.

Key words: mucociliary clearance, cilia, microtubules, mucociliary transport, liquid nitrogen. 
клетку, отделяют ее от других образований. Они разделяют ее на множество отдельных субъединиц, обеспечивая сохранность специфических физико-химических условий. По обе стороны мембран концентрация растворенных веществ, электрический потенциал, кислотность, даже температура неодинаковы. Мембраны выполняют специализированные функции. Плазматическая мембрана состоит из билипидного слоя с включенными молекулами белка. Липидная молекула представлена гликои фосфолипидами и состоит из «головки» и двух «хвостов». Белки выполняют роль рецепторов, осуществляют транспортную функцию, но большая часть представлена ферментами.

\section{Наивысшей}

активностью обладает мембрана. структуру $и$ рецепторную, барьерную,

ферментативной митохондриальная факторы меняют ункции мембраны: контактную транспортную, ферментативную [4]. Наиболее часто патогенны меняют ее проницаемость. Клеточные мембраны распадаются, что является основной причиной разрушения. Повышение проницаемости резко нарушает транспортную функцию мембран, работу ионных насосов.

Поддержание градиента ионов внутри и вне клеток является энергозависимым процессом. Снижение уровня АТФ, нарушение активности $\mathrm{Na}^{+}-$ и $\mathrm{K}^{+}$зависимой аденозинтрифосфатазы приводит к выходу $\mathrm{K}^{+}$из клетки, вхождению $\mathrm{Na}^{+}$и $\mathrm{Ca}^{2+}$ из окружающей среды [5]. Калий покидает клетку при повреждении липидного слоя под влиянием гипоксии, когда снижается синтез АТФ, при механическом повреждении и интоксикациях, реакциях антиген-антител на поверхности клеток. Ингибиция активности $\mathrm{K}^{+}-, \mathrm{Na}^{+}-$зависимой АТФ-азы сопровождается уменьшением мембранного потенциала, определяющего многие реакции клетки. Проникновение в клетку ионов натрия и хлора повышает осмотическое давление, увеличивает приток воды, мембрана растягивается вплоть до разрыва. Даже если этого не происходит, липидный слой все равно теряет свои барьерные свойства [7].

Опасным для липидного слоя мембраны является перекисное окисление липидов, оно индуцируется свободными радикалами. Пероксидное окисление может быть усилено прооксидантами (ионами двухвалентного железа, некоторыми ферментами, избытком $\mathrm{O}_{2}$ ) и, наоборот, ослаблено антиоксидантами (витамины E, A, соединения селена, ферменты каталаза, пероксидаза, супероксидисмутаза) [1]. Свободнорадикальное окисление липидного слоя приводит к нарушению барьерных свойств протоплазматических мембран, увеличению ионной проницаемости самого липидного слоя. органоидом являются митохондрии. Они являются энергосберегающими структурами клетки. В одной клетке может содержаться от 50 до 5000 митохондрий, что зависит от ее функционального состояния. Каждая из них состоит из двух мембран - внутренней и наружной. Наружная мембрана гладкая, окружает органоид; внутренняя образует многочисленные складки - кристы, которые отграничены от наружной жидкой прослойкой. Процесс окисления - передача электронов от окисляемой молекулы окислителю (молекулярному кислороду) осуществляется на внутренних мембранах митохондрий.

Энергию, освобождаемую при окислении молекул органических веществ, митохондрии используют для синтеза АТФ - универсального клеточного аккумулятора. Он образуется путем присоединения остатка фосфорной кислоты к аденозиндифосфату, а сам процесс получил название окислительного фосфорилирования. Химическая энергия АТФ трансформируется в механическую,электрическую,осмотическуюит.д.

Митохондрии первыми подвергаются изменениям при различных патологических состояниях клеток (гипоксия, интоксикация и др.). В клетке под действием патологического процесса происходит разобщение дыхания и фосфорилирования. Энергия окисления рассеивается, снижается образование АТФ, затухают все энергозависимые процессы [10]. Коэффициентполезногодействия «энергетической машины» снижается при переохлаждении, когда организму необходимо больше тепловой энергии для поддержания температурного гомеостаза, при лихорадке - процессе активного повышения температуры и последующего ее поддерживания на высоком уровне.

Наибольшее значение имеют такие изменения как набухание митохондрий, их конденсация, фрагментация, появление митохондриальных включений белковых кристаллов, липидных веществ, очагов обызвествления. Они отражают развитие неспецифических реакций митохондрий на повреждение. Увеличение числа митохондрий связывают с усилением окислительного фосфорилирования при активации, вызванной восстановлением поврежденных клеток. Уменьшение количества митохондрий в клетках свидетельствует о деструктивных атрофических процессах. В патологически измененных клетках могут обнаруживаться митохондрии гигантских размеров за счет слияния или гипертрофии, соответственно увеличиваются и размеры крист. При дефиците витамина С в рационе наблюдают слияние многих митохондрий вследствие повреждения их мембран перекисными соединениями. 
и редуцированные кристы. Число крист в митохондриях отражает их функциональную активность: чем она выше, тем больше крист и, наоборот, чем меньше активность митохондрий, тем меньше крист. В условиях патологии митохондрии могут менять локализацию, скапливаться вокруг ядра и располагаться по периферии цитоплазмы [10].

Ядро клетки является обязательным компонентом клетки, это хранитель генетической информации с помощью которой происходит управление синтезом белка, морфологическими и физиологическими процессами. Влияние патогенных процессов на клетку сопровождается некоторыми типическими структурными и функциональными изменениями ядра [22]. Репаративная регенерация сочетается с кратным увеличением числа хромосом, увеличением его размеров.

Нарушение внутренних процессов сочетается с дисфункциональным токсическим набуханием ядра. При дистрофических процессах, воспалении, новообразованиях наблюдается полиморфизм ядер, их деформация плазматическими включениями или выпячиванием в цитоплазму [1]. Под действием холодового стресса происходит изменение функций реснитчатых клеток, приводящее к снижению их количества. Холодный воздух зимой способствует снижению местной иммунологической резистентности и очистительной способности мерцательного эпителия дыхательных путей. Эпителий дыхательных путей является модулятором защитных механизмов при воспалении [21]. Реснитчатые и бокаловидные клетки участвуют в защите мукоцилиарного клиренса от микроорганизмов и различных неблагоприятных воздействий окружающей среды [33]. По количественному составу в трахее реснитчатые клетки преобладают над бокаловидными в соотношении 4:1. Перемещение слизистых выделений осуществляется с помощью ресничек, располагающихся на апикальной поверхности клеток покровного мерцательного эпителия [14]. Существуетзначительное количествозаболеваний верхнихи нижних дыхательных путей, при которых происходит нарушение транспортной функции реснитчатого эпителия в результате избыточного выделения слизи бокаловидными клетками [13]. При различных воспалительных реакциях происходит увеличение образования слизи за счет подслизистых желез и гиперсекреции бокаловидных клеток. Слизь, образующаяся на поверхности эпителия, обволакивает реснитчатый эпителий, нарушая мукоцилиарный клиренс, при котором он с трудом выполняет свои функции по очистке накопившихся выделений. Таким образом, слизь покрывает значительную площадь поверхностного эпителия трахеи, оставляя при этом незначительные отдельные пласты, нарушая эвакуаторную функцию мерцательного эпителия [12]. Застойные явления в трахее и бронхах образуют слизистую пробку. Это приводит к микробному обсеменению данного участка и развитию воспалительного процесса на поверхности трахеи [24]. После этого данный участок подвергается местному иммунному ответу со стороны организма с возникновением клеточной инфильтрации. В дальнейшем количество слизи увеличивается, усугубляя функциональные возможности реснитчатого эпителия. В результате воспалительного процесса происходит увеличение толщины стенки трахеи, это в свою очередь повышает сопротивление в дыхательных путях, вызывая в последующем ее непроходимость. Клеточныйпластповерхностного эпителия на данном участке подвергается воздействию окислителей, которые образуются эндогенно и экзогенно, они становятся очень восприимчивы к реактивным формам кислорода.

$\begin{array}{rcr}\text { Помимо } & \text { экзогенных } & \text { источников } \\ \text { окислительного } & \text { стресса } & \text { происходит }\end{array}$
активирование макрофагов нейтрофилов с образованиемактивныхформкислорода, вызывая перекисное окисление липидов, разрушающих клеточную мембрану и ухудшающих функцию клеточных элементов [35]. В результате этого происходит снижение пролиферации клеток с образованием метаплазии реснитчатых клеток. Разрушаются мембранные рецепторы с потерей местной антиоксидантной защиты. Благодаря колебаниям ресничек мерцательного эпителия создаются благоприятные возможности для удаления слизи, микробов и патогенных частиц с поверхности клеток, играющих защитную роль в организме, формируя таким образом защитный барьер от действия патогенных факторов [16, 32].

Ухудшение мукоцилиарной функции приводит сначала к дискинезии мерцательного эпителия, а потом к развитию хронических заболеваний [15]. Вследствие дисфункции слизистой оболочки трахеи клетки истощаются и высыхают, замедляется их регенерация. В лабораторных исследованиях на биоптатах измеряют частоту биения ресничек [27]. Однако, этих данных оказывается недостаточно для диагностики и диагноза. Крайне важна морфологическая характеристика покровного эпителия мерцательных клеток.

Чтобы выявить причины нарушения колебательных свойств ресничек при патологии, необходимо понять, за счет каких внутренних механизмов оно возникает в норме и патологии [17]. Недостаточность экспериментальных данных о причинах возникновения нарушений двигательной активности реснитчатого аппарата со стороны морфологических изменений, происходящих в реснитчатых клетках, требует специальных методов измерения и обработки 
полученных результатов [26, 28, 31]. Решению этих задач способствует исследование внутренней структуры мерцательных клеток [37]. Очень часто в ходе манипуляции с исследуемым материалом появляются артефакты, мешающие в полной мере добиться качества исследования материала, увеличивается время от начала обработки среза до выявления патологий в объекте. Чтобы быстро диагностировать заболевание верхних дыхательных путей, используются различные методы, помогающие в короткие сроки определитьглубинупоражения тканейиназначить эффективное лечение. Одним из таких методов является метод замораживания скалывания.

В ЦНИЛ Амурской ГМА разработан экспресс крио-метод с применением жидкого азота и электронной растровой микроскопии для изучения биологических тканей. Его главным преимуществом является то, что на первый план выносится быстрота и качество исследования при минимуме затраченного времени. Этот метод позволяет сократить время от начала обработки до исследования объекта и дает возможность изучить внутреннее строение клеточных мембран, а также использовать его во избежание искажений для исследования замороженных нефиксированных срезов за счет образовавшегося льда, который не вызывает нарушения внутренней ультраструктуры и исключает риск появления артефактов.

Еще одним преимуществом данного метода является то, что обычные изображения биологической ткани под высоким вакуумом требуют покрытия среза проводящим металлом, который затеняет информацию об образце независимо от вида ткани. Сканирующая электронная микроскопия с применением метода замораживания скалывания позволяет исследовать поверхность ткани и выявлять все изменения, происходящие в ней при действии патологического процесса.

\begin{tabular}{lcr}
\multicolumn{2}{c}{ Исследование ресничек } & мерцательного \\
эпителия с прижизненным & сохранением \\
достаточного & количества & реснитчатого
\end{tabular}
эпителия может иметь огромное значение в диагностике заболеваний органов дыхания. Поэтому, несмотря на успехи, достигнутые многими учеными в области прижизненного изучения активности реснитчатого эпителия, эти исследования могут быть дополнены информацией, показывающей происходящие нарушения во внутренней ультраструктуре мерцательных клеток, и выявлении их с помощью морфологического изучения и экспресс-метода.

\section{Литература}

1.АдоА.Д. Патофизиология:учеб.//М.:Триада-Х,2006.574с.2.

2. Винницкий М.Е., Пономарев В.П. Исследование механических свойств слизистой оболочки //3-я всесоюзная конференция по проблемам биомеханики: Тез. докл Всесоюз. науч. конф. 21-24 июня 1983 г. Рига, 1983. т. 1. С.
145-147.

Висмонт Ф.И. Общая патофизиология: учеб. пособие // Минск : Выш. шк., 2011. 364 с.

4. Захарова Г.П., Шабалин ВВ., Лащов А.А. Современные методы оценки нарушений мукоцилиарного транспорта в диагностике хронических риносинуситов // Вестн. оториноларингологии. 1998. т. 4. С. 53-54.

5. Литвицкий, П.Ф. Патофизиология : учеб. // 4-е изд., перераб. и доп. М.: ГЭОТАР-Медиа, 2008. С. 43-58.

6. Пискунов С.3., Завьялов Ф.Н., Ерофеев Л.Н. Исследование мукоцилиарной транспортной системы слизистой оболочки носа у здоровых лиц // Российская ринология, 1995, №3-4 . С. 60-62.

7. Сагалович Б.М. Физиология и патофизиология верхних дыхательных путей. М., 1967. 219 с.

8. Соколов Е.И., Зыков К.А., Вешкина А.И. и др.

Сравнительная морфологическая характеристика слизистой оболочки бронхов у больных хроническим обструктивным бронхитом и бронхиальной астмой // Архивы патологии 2000. Т. 62. Вып. 4. С. 31-37.

9. Шабалин В.В. Биомеханика движений реснитчатых клеток мерцательного эпителия. //Научно-технические ведомости СПбГТУ. 1998. N2-3. СПб., изд. СПбГТУ. С. 68-71.

10. Шанин В.Ю. Патофизиология критических состояний // СПб.: ЭЛБИ-СПб, 2003. 436 с.

11. Andersen I., Camner P., Jensen PL., Philipson K., Proctor D.L. A comparison of nasal and tracheobronchial clearence // Archs. environ. Hlth. 1974. Vol.29. P. 290.

12. Barnet B., Miller C.E. Flow induced by biological mucociliary systems // Ann. N.Y. Acad. Sci. 1966. Vol. 130. P. 891.

13. Barry P.W., Mason N.P., O'Callaghan C. Nasal mucociliary transport is impaired at altitude //European Respiratory Journal. 1997. Vol. 10. N1. P. 35-7.

14. Barton C., Raynor S. Analytical investigation of cilia iduced mucous flow // Bulletin of Mathematical Biophysics. 1967. Vol. 29. N3. P. 419-428.

15. Bertrand B., Collet S., Eloy P. et al Secondary ciliary dyskinesia in upper respiratory tract //ActaOtorhinolaryngol. Belg. 2000. Vol.54(3). P. 309-316.

16. Blake J.B., Winet $\mathrm{H}$. On the mechanics of mucociliary flows // Biorheol. 1980. Vol. 17. N11. P. 125-134.

17. Dalhamn T. Mucous flow and ciliary activity in the trachea of healfy rats and rats exposed to respiratory irritant dases // Acta Physiol. Scand. 1956. Vol.36. Suppl. 123.

18. Donovan BY, Lid B, Wong HuaMao. Mucociliary dysfunction: real and potential pathogenic mechanisms in mucus, ciliary activity and mucociliary interaction. Pediatr Pulmonol 1997; Suppl 14: 108.

19. Hady M.R. A., Shehata O., Hassan R. Nasal mucociliary function in differnt diseases of th nose //J. Laryngol. Otol. 1983. Vol.97. P. 497-502.

20. Johnson N.T., Villaion M., Royce F.H., Hard R., Verdugo P. Auto-regullation of beat frequency in respiratory ciliated cells: demonstration by viscous loading //Am. Rev. Respir. Dis. 1991. Vol.144. P. 1091-1094.

21. Kao C.H., Jiang R.S., Wang S.J. Yeh S.H. Influence of age gender and ethnicity on nasal mucociliary clearance function //Clinical Nuclear Medicine. 1994. Vol.19. N9. P. 813-816.

22.Konrad F., Schiener R., Marx T., Georgieff M. Ultrastructure and mucociliary transport of bronchial respiratory epithelium in intubated patients // Intensive Care Medicine. 1995. Vol.21. N6. P. 482-489. 
23. Liron N., Rozenson M. Muco-ciliary transport // J. Submicrosc. Cytol. 1983. Vol.15. P. 317-321.

24. Lorenzi G., Bohm G.M., Guimaraes E.T., Vaz M.A., King M., Saldiva P.H. Correlation rheologic properties and in vitro ciliary transport of rat nasal mucous //Biorheol. 1992. Vol.29. P. 433-440.

25. Lucas A.M. Influence of temperature on ciliary beat //J. Morphol. 1932. Vol.53. P. 265-276.

26. Mason J.D., Aspden T.J., Adler J., Jones N.S., Ilium L. Measurement of nasal mucociliary transport rates on the isolated human inferior turbinate // Source Clinical Otolaryngology. 1995. Vol.20. N6. P. 530-535.

27. McCullagh C.M., Jamieson A.M., Blackwell J., Gupta R. Viscoelastic properties of human tracheobronchial mucin in aqueous solution // Biopolymers. 1995. Vol.35. P. 149-159.

28. Puchelle G., Aug F., Pham O.T., Bertrand A. Comparison of three methods for measuring nasal mucocilliary clearance in man //Acta Otolaryngol. 1981. Vol.91. N3-4. P. 297-303.

29. Puchelle E., Zahm J.M., Sadoul P. Influence of rheological properties of human bronchial secretions on the ciliary beat frequency //Biorheol. 1983. Vol.20. N4. P. 383-384.

30. Reimer A., Huberman D., Klementsson K., Toremalm N.G. The mucociliary activity of the respiratory tract //Acta Otolaryngol. 1981. Vol.91. P. 139-148.

31. Riechelmann H., Kienast K., Schellenberg J., Mann W.J. An in vitro model to study effect of airborne pollutants on human mucociliary activity // Rhinology. 1994. Vol.32. P. 105-108.

32. Satir P., Sleigh M. A. The physiology of cilia and mucociliary interaction // Annu. Rev. Physiol. 1990. Vol.52. P. 137-155.

33. Silberberg A. Bioreological matching: mucociliary interaction and ephitelial clearance//Reol. Acta. 1982. Vol.21. N4-5. P. 605-606.

34. Sleigh M.A. Movement and coordination of tracheal cilia and the relation of these to mucus transport //Cell. Motil. (Suppl.) 1982. Vol.1. P. 19-24.

35.Tournier J.M, de Bentzmann S., Gaillard D., Puchelle E. Morphogenesis and modifications of the respiratory epithelium //Arch. Int. Physiol. Biochem. Biophys. 1992. Vol.100. P. 47-49.

36. Wanner A, Salathe M, O'Riordan TO. Mucocillyary clearance in the airways // Am J Respir Crit Care Med 1996. Vol.154. P. 1868-902.

37. Yager J., Chen T.-M., Bulfano M. Measurement of frequency of ciliary beats of human respiratiry epithelium // Ibid. 1978.

Vol.73. P. 627-633.

Статья поступила в редакцию 12.11.2017

Статья поступила в редакцию 12.11.2017

\section{Координаты для связи}

Горбунов Михаил Михайлович, к. б. н., М. н. с. ЦНИЛ ФГБОУ ВО Амурская ГМА Минздрава России.

Целуйко Сергей Семёнович, Д. м. Н., профессор, проректор по НР, заведующии кафедрой гистологии и биологии ФГБОУ ВО Амурская ГМА Минздрава России.

Зиновьев Сергей Викторович, с. н. с. ЦНИЛ ФГБОУ ВО Амурская ГМА Минздрава России.

Почтовый адрес ФГБОУ ВО Амурская ГМА Минздрава России: 675000, г. Благовещенск, Амурской области, ул. Горького, 95. E-mail: agma@ya.ru

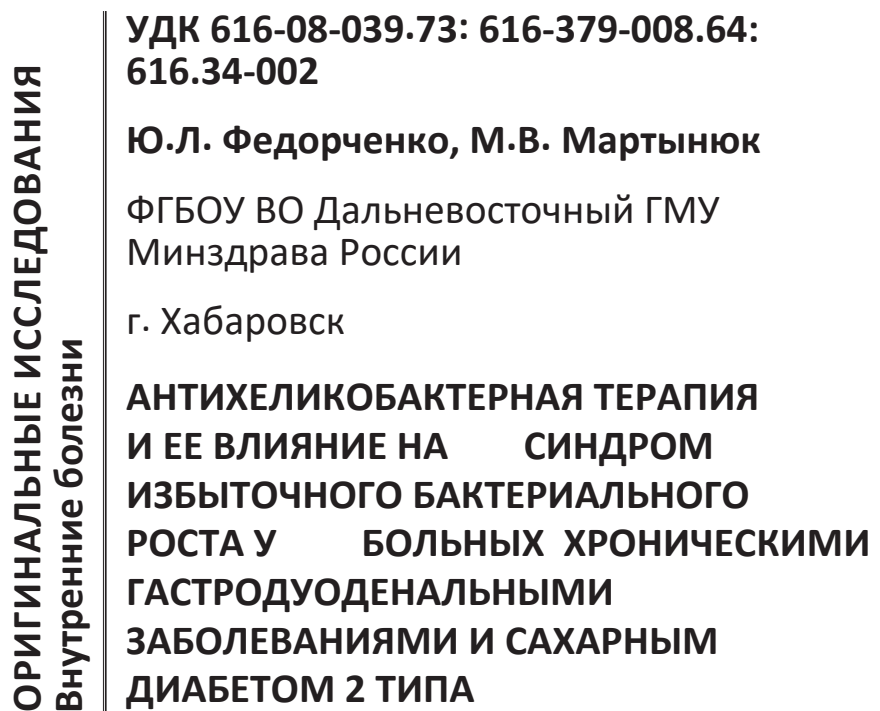

Инфекция Helicobacter pylori (H.pylori) в настоящее время считается одним из основных факторов, приводящих к развитию хронических воспалительных заболеваний верхних отделов желудочно-кишечного тракта [9]. Клиническая значимость данной инфекции состоит в определении ее ведущей роли в формировании язвенной болезни, хронического гастрита, MALTлимфомы, рака желудка [5]. В разных регионах России инфекция H.pylori обнаруживается у 65-92\% взрослого населения [4].

Больные сахарным диабетом 2 типа (СД2), согласно ряду публикаций, относятся к группе риска по инфицированию хеликобактериозом

Резюме В статье представлен анализ эффективности различных современных схем антихеликобактерной терапии у 106-и больных с хроническими гастродуоденальными заболеваниями в сочетании с сахарным диабетом 2 типа. Оценивали динамику клинической картины, эндоскопическую ремиссию, эффективность эрадикации helicobacter pylori. Изучали влияние схем антихеликобактериальной терапии на синдром избыточного бактериального роста в кишечнике (СИБР) у данных больных. Установлено, что тройная 14-дневная терапия первой линии с рабепразолом, амоксициллином и кларитромицином привела к эрадикации возбудителя только в 80,6\% случаев. Усиление этой схемы пробиотиком и препаратом висмута увеличило эрадикацию до 94,1\%. Наиболее эффективной была схема сочетанной усиленной пробиотиком терапии: рабепразол, амоксициллин, кларитромицин и метронидазол - 97,2\%. Последние две схемы были наиболее эффективными и по лечению СИБР у данных пациентов, уменьшая число таких больных на 35,3-50\%.

Ключевые слова: helicobacter pylori, хронические гастродуоденальные заболевания, сахарный диабет 2 типа, эрадикационная терапия, синдром избыточного бактериального роста. 